\title{
Where no one has gone before
}

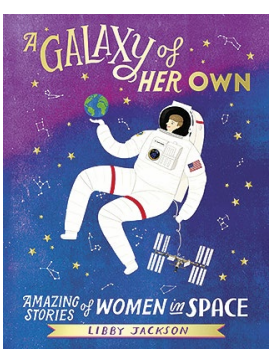

\author{
A Galaxy of \\ Her Own: Amazing \\ Stories of Women \\ in Space \\ by Libby Jackson \\ CENTURY: 2017. 144 pp. \\ E16.99
}

ast year saw the 50th anniversary of 2001: A Space Odyssey, a movie that gave us an artistic glimpse into a future in space. This future, like the perception of 1960s NASA, was entirely male. Kubrick and Clarke presented a vision of men, served coffee by women, calling home to their families while waiting for a space flight. The film scores very low on the Bechdel test, but this is entirely in keeping with the folklore of humanity's first decades in space where testosterone-fuelled explorers were guided to the moon by waistcoat-wearing, chain-smoking men.

This is an impression that $A$ Galaxy of Her Own hopes to reverse. The book tackles this narrative with 50 illustrated biographies highlighting some of the key women who have helped define humanity's new frontier. This is 'on trend', as even a momentary glance at a bookshop will reveal a host of similar titles attempting to redress the gender balance of history. Goodnight Stories for Rebel Girls and Women in Science have proved popular in recent years, and publishers are clearly tapping into a rich seam of interest and popular feeling.

But while most of these books are generic in their appeal and often read like a Wikipedia entry dressed as a bedtime fable, A Galaxy of her Own is filled with a passion for the subject from an author who has lived and breathed the air of the world's space agencies. At the start, Libby Jackson, the current head of microgravity and human space flight at the UK Space Agency, tackles her own fascinating space story with the typical understatement of a British civil servant. In the pages that follow, her enthusiasm and love for the subject shines through. This book is a call to become involved, a glorious tapestry of examples that tempts younger readers to follow in the footsteps of the remarkable people represented in its pages.

It is a difficult book to categorize: is it aimed at young people? Yes and no. It is clearly a book that appeals to a younger reader. It is not an in-depth treatise on the role of women in the space industry, but it sits well above the level of a simple children's book. Perhaps it is best described as a family book, a book that adults will enjoy leafing through as much as children and that parents will certainly enjoy reading with their offspring.

The book is divided into historical periods, beginning with the pre-1957 origins of the space race and ending with a look to the near future as it is now unfolding. Each personality is presented with a quote and a short biography that places them in context, provides the salient facts of their role and tells an interesting story. It includes many of the 'usual suspects', Valentina Tereschkova, Helen Sharman, Sally Ride and Mae Jameson are all present, as are increasingly better-known names such as Dottie Lee or Margaret Hamilton.

One thing that stands out immediately as you pick up this volume is the unique commissioned artwork from artists at the London College of Communication. There is one for each character and this art is one of the real treats of this book, showcasing as many styles as there are stories. Many are stunning visual treats, while some are a little more esoteric. All are thought-provoking though, giving this book a visual quality that helps put it above the others of this kind and helps to draw you into the stories, setting you off on this voyage of discovery.

There are many great and fascinating stories in this book, especially those that are not often heard, where, to the author's credit, we leave the familiar path of astronauts and scientists. Examples include Nichelle Nichols of Star Trek who takes on NASA's gender and race issues helping them recruit the next generation of astronauts, production of the Apollo spacesuit by women who normally made underwear in The International Latex Company, and the wonderfully poignant story of the Waltham 'Little old Ladies' expert textile and watch makers who created the rope memory for Apollo and whose names are almost entirely unrecorded.

There is also a clear desire on the author's part to move away from the Euro-Americacentric story. Noriko Shiraishi, JAXA launch conductor, and Chiaki Mukai, Japan's first woman in space, are here hammering home not just the gender focus, but the relatively unknown nature of Japan's space programme, a story that really needs to be told more widely.

Pre-1957 is where the book is at its weakest. Mary Sherman Morgan clearly belongs, a brilliant chemist who literally launched the US space programme. Less obvious are Emilie du Chatelet - the eighteenth-century French translator of Newton - and the perennial favourite of popular science books Ada Lovelace, as historical debate about her role in computing is a minefield that is constantly oversimplified. Jacquline Cochran, a brilliant, gifted pilot and business woman is difficult to apply directly to space even in the text. Their links to gravity, computing and flying are all fascinating stories, but are they truly a part of the space story? This is a debate that any book like this will generate and that is no bad thing. Earlier periods of science history are particularly difficult when writing about the involvement of women, indeed this is one of the points being made by the author.

This is a beautiful and timely book that tackles the smoke-filled testosterone image of Apollo head on. It is a joy to read, especially with children. My own have come to adore it: a staple of rainy afternoons. It isn't an in-depth study, but the breadth and the huge range of roles discussed achieves the author's aim. There are more women in this story than we ever recognize and it must have been difficult to decide who to include and who to leave out. The discussion it provokes may be this book's finest achievement.

Reviewed by Paul Hill

Science explainer and performer.

e-mail:paul@siriusastronomy.co.uk

Published online: 1 March 2019

https://doi.org/10.1038/s41567-019-0453-4 